\title{
A prospective cohort study of perinatal outcomes: pregnancies with isolated oligohydramnios versus normal pregnancies
}

\author{
A C M Musthaq ${ }^{a}$, K A S U A Kodithuwakku ${ }^{b}$, M R F Shireen ${ }^{c}$, W Abeykoon ${ }^{d}$
}

\begin{abstract}
Background: Pregnancies with oligohydramnios at term in the absence of fetal and maternal compromise pose a dilemma in management. Evidence regarding the outcome of these pregnancies are controversial, and it is one of the common reason for early induction of labour in the fear of adverse perinatal outcome. Outcomes of such pregnancies are not adequately studied in Sri Lankan setting.

Objective: To compare the perinatal fetal outcomes of isolated oligohydramnios with normal pregnancy at term among women who were admitted to Teaching Hospital Kandy.

Methods: A prospective cohort study was carried out. All the pregnant mothers admitted to ward 7 Teaching Hospital Kandy at term were routinely scanned for fetal growth and amniotic fluid volume. Women with isolated oligohydramnios $(n=70)$ and without any other pregnancy-related complications were selected as controls. Two controls (normal pregnancy $n=140$ ) were selected per case matching the age and parity. These pregnant mothers were followed up from the date of admission to discharge. Immediate perinatal fetal and postnatal outcomes were assessed. Data were entered and analyzed by SPSS 22.0.
\end{abstract}

Results: The majority of the patients (58.5\%) with isolated oligohydramnios were induced early, and a significant number of these patients have undergone emergency caesarean section $\left(X^{2}=12.98, p=0.003\right)$. Although pregnancies with isolated oligohydramnios tends to have more CTG abnormalities, it was not statistically significant $\left(X^{2}=4.29, p=0.12\right)$. But, the incidence of significant meconium-stained liquor was higher than normal pregnancies $\left(X^{2}=6.02, p=0.049\right)$. However, the fetal outcome APGAR $<7$ at 5 minutes $\left(X^{2}=0.33, p=0.95\right)$ short term perinatal morbidities $\left(X^{2}=0.29, p=0.59\right)$ were shown no statistical difference between both group. Neonatal special care baby unit admissions were higher in pregnancies with isolated oligohydramnios $\left(X^{2}=23.56\right.$, $\mathrm{p}=0.0001$ ).

Conclusion and recommendation: Compared to normal pregnancies, pregnancies with isolated oligohydramnios didn't show any statistically significant difference in perinatal outcome. Oligohydramnios itself doesn't indicate the fetal compromise when other growth parameters were normal. However, as there are controversies in management further researches are needed in this field.

Key words: isolated oligohydramnios, amniotic fluid index, perinatal outcome

Sri Lanka Journal of Obstetrics and Gynaecology 2019; 41: 75-80

DOI: http://doi.org/10.4038/sljog.v41i3.7895

${ }^{a}$ Clinical Fellow in Obstetrics and Gynaecology, St Georges University Hospital NHS Trust, London, United Kingdom.

b Senior Registrar in Obstetrics and Gynaecology, Sunshine Hospital, Victoria, Australia.

c Registrar in Dermatology, Teaching Hospital Karapitiya, Sri Lanka.

d Consultant Obstetrician and Gynaecologist, Teaching Hospital Kandy, Sri Lanka.

Correspondence: ACMM, e-mail: <drmusthaq@ hotmail.com>

Received June 2019 and revised version accepted $4^{\text {th }}$ August 2019.

https://orcid.org/0000-0002-0562-8417

Competing interest: The authors report no conflict of interest

This is an open-access article distributed under the terms of the Creative Commons Attribution 4.0 International License, which permits unrestricted use, distribution and reproduction in any medium provided the original author and source are credited. 


\section{Introduction}

Amniotic fluid bathes the fetus, and is essential for proper growth and development. It protects the fetus from physical trauma by functioning as cushion and helps in fetal lung growth. In early gestation, amniotic fluid is generated from maternal plasma and passes through the fetal membranes by osmotic and hydrostatic forces. Following the keratinization of skin and the development of kidneys, fetal urine is the main contributor of amniotic fluid. The volume of amniotic fluid increases gradually towards the term and peaks at 36 to 37 weeks of gestation. After 38 weeks, the volume appears to be gradually declining ${ }^{1}$.

An abnormally high amniotic fluid volume (polyhydramnios AFI >25) and abnormally low amniotic fluid volume (Oligohydramnios AFI < 5) are associated with various maternal and fetal conditions. The amniotic fluid index (AFI) is measured by dividing the uterus into four quadrants and the deepest unobstructed vertical pockets of fluid are measured in centimeters and then added to calculate. The normal value ranges from $5 \mathrm{~cm}$ to $25 \mathrm{~cm}^{2,3}$.

Oligohydramnios is associated with intrauterine growth restriction, intrauterine infection, pre-labour rupture of membranes, drugs and fetal renal abnormalities ${ }^{4}$ for this study isolated oligohydramnios is defined as reduced volume of amniotic fluid (AFI $<5 \mathrm{~cm}$ ) in the absence of other pathologies. Usually, it is an incidental finding and poses a major challenge in obstetric management when it is detected. It is one of the commonest reasons for repeated antenatal fetal surveillance and early induction of labour. The incidence of oligohydramnios varies from less than $0.5 \%$ to above $5 \%$ depending on the study population and the variations in the definition of oligohydramnios.

Current literature reveals conflicting evidence regarding the outcomes of pregnancies complicated with isolated oligohydramnios. While some prove adverse outcomes and others not. However, most of the obstetrics units in Sri Lanka induce labour early in patients with isolated oligohydramnios.

\section{Literature review}

A study done by Elsandabesee et al in 2007 at Norwich, among 94 women to assess the obstetrician's attitude towards isolated oligohydramnios at term revealed $45 \%$ women had labour induced and $4.5 \%$ had undergone elective caesarean section. The emergency caesarean section rate was more than twice (13.5\%) compared to $6 \%$ in the low-risk group. But there was no increase in perinatal morbidity in babies who had isolated oligohydramnios ${ }^{5}$.

A similar study done by Bachhav and Waikar in India among 180 pregnant women revealed that 5 minute APGAR score was less than 7 among 34\% of pregnancies with isolated oligohydramnios compared to $11 \%$ among control group. Also, $65 \%$ of the study group had a non-reactive non-stress test compared to $24 \%$ in the control group. Caesarean section rate also doubled compared to the control group (66\% vs $33 \%)^{6}$.

Also, another prospective study done by Alchalabi divided 180 pregnant women into two groups who were between 37 and 42 weeks' of gestation and were admitted for induction of labour. The women in one group had an AFI $\leq 5 \mathrm{~cm}(\mathrm{n}=66)$ and the women in the other group had an AFI of $>5 \mathrm{~cm}$. The two groups had comparable demographic and obstetric characteristics before induction. The women in the isolated oligohydramnios group had a statistically significant increased rate of cesarean section secondary to fetal compromise in labour (27.3\% vs 5.5\%; OR 6.75, $95 \%$ CI $1.8-23.2 ; \mathrm{p}=.004)^{7}$.

However, recent (2016) systematic review and metaanalysis done by Shrem et al included 2,414 patients with isolated oligohydramnios found that they are higher risk of labour induction (OR 7.56, CI 4.58-12.48) and Cesarean sections (OR 2.07, CI 1.77-2.41) ${ }^{8}$. Also, there were higher rates of an Apgar score $<7$ at 1 and 5 min (OR 1.53, CI 1.03-2.26, and OR 2.01, CI 1.33.09 , respectively) and admission to the neonatal intensive care unit (OR 1.47, CI 1.17-1.84). However, there were no statistically significant differences in cord $\mathrm{pH}<7.1$ and meconium-stained amniotic fluid. It concludes that isolated oligohydramnios at term is associated with significantly higher rates of labor induction, cesarean sections, and short-term neonatal morbidity.

\section{Methodology}

A prospective cohort study was conducted at ward 7 Teaching Hospital, Kandy. Pregnant mothers who were admitted at term (between 37 weeks to 42 weeks of gestation) to ward 7 Teaching Hospital, Kandy was selected for the study. All the pregnant mothers admitted to ward 7 at term was offered a routine ultrasound 
scan whenever possible. Fetal growth parameters and estimated fetal weight was calculated using the Hadlock formula. Routine ultrasound scan included measurements of fetal biparietal diameter, head circumference, abdominal circumference, and femur length.

The amniotic fluid index was measured by dividing the uterus into four imaginary quadrants. The linea niagra is used to divide the uterus into right and left halves. The umbilicus serves as the dividing point for the upper and lower halves. The transducer was kept parallel to the patient's longitudinal axis and perpendicular to the floor. The deepest, unobstructed, vertical pocket of fluid is measured in each quadrant in centimeters. The four pocket measurements were added to calculate the AFI.

\section{Exclusion criteria}

1. Pregnant mothers who were diagnosed with abnormal Doppler studies

2. Admitted with prelabour rupture of membranes

3. Diagnosed patient with fetal abnormalities

Pregnant mothers who were found to have normal growth (estimated fetal weight $>10^{\text {th }}$ centile for the gestation) with reduced amniotic fluid index (less than 5) were included in the study group. Suspected cases and controls were rescanned by the principal investigator before including to the study population to exclude operator bias. Two mothers who had similar parity and gestation, but with otherwise low-risk pregnancy and normal ultrasound scan findings were included in the control group. 70 pregnant mothers with isolated oligohydramnios and 140 controls were selected.

Both of these groups were followed up from admission to discharge and events were recorded and maternal and fetal outcomes were assessed. Data was collected using a data extraction sheet.

\section{Outcome measures}

The following fetal and maternal parameters were compared. Induction of labour, presence of significant meconium-stained liquor, CTG abnormalities, Fetal APGAR score, admission to special care baby unit and incidence of cesarean delivery in both groups.

\section{Results}

70 pregnancies with isolated oligohydramnios compared to 140 low-risk pregnancies (Table 1,2). The mean age of the study group was 27.64 (SD - 4.28) and the mean age of controls was 26.55 (SD- 4.56). The majority $(72.8 \%)$ of them were in their first pregnancies. $22.8 \%, 4.4 \%$ of them were in their second and third pregnancies respectively.

\section{Table 1. Description of characteristics of the study population}

\begin{tabular}{|l|l|l|}
\hline & \multicolumn{1}{|c|}{ Cases } & Control \\
\hline Number of participants & 70 & 140 \\
\hline Mean age & 27.64 & 26.55 \\
\hline Slandered deviation & 4.284 & 4.559 \\
\hline
\end{tabular}

Table 2. Distribution of parity of pregnant mothers in the study group

\begin{tabular}{|l|c|c|c|}
\hline & Cases (\%) & Control (\%) & Total \\
\hline Primi & $\begin{array}{c}51 \\
(72.8 \%)\end{array}$ & $\begin{array}{c}102 \\
(72.8 \%)\end{array}$ & $\begin{array}{c}153 \\
(72.8 \%)\end{array}$ \\
\hline Para 1 & $\begin{array}{c}16 \\
(22.8 \%)\end{array}$ & $\begin{array}{c}32 \\
(22.8 \%)\end{array}$ & $\begin{array}{c}48 \\
(22.8 \%)\end{array}$ \\
\hline Para 2 & $\begin{array}{c}3 \\
(4.4 \%)\end{array}$ & $\begin{array}{c}6 \\
(4.4 \%)\end{array}$ & $\begin{array}{c}9 \\
(4.4 \%)\end{array}$ \\
\hline Total & 70 & 140 & 210 \\
\hline
\end{tabular}

\subsection{Induction of labour}

A higher number of pregnancies with isolated oligohydramnios (58.5\%) were induced early compared to the control group and it was statistically significant $\left(\mathrm{X}^{2}-108.5, \mathrm{p}<0.001\right)$. Four mothers with isolated oligohydramnios refused induction and had undergone an elective caesarean section. 
Table 3. Comparison of labour induction between two groups

\begin{tabular}{|l|c|c|c|}
\hline Spontaneous & $\begin{array}{c}\text { Cases } \\
(\%)\end{array}$ & $\begin{array}{c}\text { Control } \\
(\%)\end{array}$ & Total \\
\hline $\begin{array}{c}27 \\
(38.5)\end{array}$ & $\begin{array}{c}86 \\
(61.4)\end{array}$ & $\begin{array}{c}113 \\
(53.8)\end{array}$ \\
\hline Early induction & $\begin{array}{c}41 \\
(58.5)\end{array}$ & 0 & $\begin{array}{c}41 \\
(19.5)\end{array}$ \\
\hline Routine induction & $\begin{array}{c}8 \\
(11.4 \%)\end{array}$ & $\begin{array}{c}54 \\
(38.6)\end{array}$ & $\begin{array}{c}62 \\
(29.5)\end{array}$ \\
\hline EL/LSCS & $\begin{array}{c}4 \\
(5.6)\end{array}$ & 0 & $\begin{array}{c}4 \\
(1.9)\end{array}$ \\
\hline Column totals & 70 & 140 & 210 \\
\hline
\end{tabular}

$\mathrm{X}^{2}$ for induction of labour 108.5, $\mathrm{p}<0.001$.

\subsection{CTG abnormalities and meconium stained liquor}

Interpretations of CTGs were done according to NICE guideline recommendations. Patients with isolated oligohydramnios were tended to have more suspicious and pathological CTG abnormalities (Table 4). 11.4\% $(\mathrm{N}=8)$ were categorized as pathological in isolated oligohydramnios group compared to $9.4 \%(\mathrm{~N}=13)$ in normal pregnancies. The results was not statistically significant $\left(\mathrm{X}^{2}-4.29, \mathrm{p}=0.12\right)$.

Table 4. Comparison of CTG abnormalities between the groups

\begin{tabular}{|l|c|c|c|}
\hline & $\begin{array}{c}\text { Cases } \\
(\%)\end{array}$ & $\begin{array}{c}\text { Control } \\
(\%)\end{array}$ & Total \\
\hline $\begin{array}{l}\text { Reactive } \\
\text { CTG }\end{array}$ & $\begin{array}{c}47 \\
(67.1 \%)\end{array}$ & $\begin{array}{c}111 \\
(79.2 \%)\end{array}$ & $\begin{array}{c}158 \\
(75.2 \%)\end{array}$ \\
\hline $\begin{array}{l}\text { Suspicious } \\
\text { CTG }\end{array}$ & $\begin{array}{c}15 \\
(21.4 \%)\end{array}$ & $\begin{array}{c}16 \\
(11.4 \%)\end{array}$ & $\begin{array}{c}31 \\
(14.7 \%)\end{array}$ \\
\hline $\begin{array}{l}\text { Pathological } \\
\text { CTG }\end{array}$ & $\begin{array}{c}8 \\
(11.4 \%)\end{array}$ & $\begin{array}{c}13 \\
(9.4 \%)\end{array}$ & $\begin{array}{c}21 \\
(10.1 \%)\end{array}$ \\
\hline Total & 70 & 140 & 210 \\
\hline
\end{tabular}

Pregnancies with isolated oligohydramnios were more likely to have a significant meconium $(12.9 \% ; \mathrm{N}=9)$ stained liquor compared to normal pregnancies $(7.1 \% ; \mathrm{N}=10)$ and it is statistically significant $\left(\mathrm{X}^{2}-6.02\right.$ and $\left.\mathrm{p}=0.049\right)$.

Table 5. Presence of meconium-stained amniotic fluid

\begin{tabular}{|l|c|c|c|}
\hline & $\begin{array}{c}\text { Cases } \\
(\%)\end{array}$ & $\begin{array}{c}\text { Control } \\
(\%)\end{array}$ & Total \\
\hline No meconium & $\begin{array}{c}49 \\
(70 \%)\end{array}$ & $\begin{array}{c}113 \\
(80.7 \%)\end{array}$ & $\begin{array}{c}162 \\
(77.14 \%)\end{array}$ \\
\hline Thin meconium & $\begin{array}{c}12 \\
(17.1 \%)\end{array}$ & $\begin{array}{c}17 \\
(12.1 \%)\end{array}$ & $\begin{array}{c}29 \\
(13.8 \%)\end{array}$ \\
\hline $\begin{array}{l}\text { Significant } \\
\text { meconium }\end{array}$ & $\begin{array}{c}9 \\
(12.9 \%)\end{array}$ & $\begin{array}{c}10 \\
(7.14 \%)\end{array}$ & $\begin{array}{c}19 \\
(9.06 \%)\end{array}$ \\
\hline Total & 70 & 140 & 210 \\
\hline
\end{tabular}

\subsection{Mode of delivery}

Four mothers requested an elective caesarean delivery among isolated oligohydramnios group. $77.1 \%$ of the study population delivered vaginally. However, 27.2\% ( $\mathrm{N}=19)$ of pregnant mothers in isolated oligohydramnios had undergone emergency caesarean section compared to $15.8 \%$ $(\mathrm{N}=22)$ in control group, which statistically is significant $\left(\mathrm{X}^{2}=12.98, \mathrm{p}=0.003\right)$. Table 6 compares the results.

Table 6. Comparison of mode of delivery

\begin{tabular}{|l|c|c|c|}
\hline NVD & $\begin{array}{c}\text { Cases } \\
(\%)\end{array}$ & $\begin{array}{c}\text { Control } \\
(\%)\end{array}$ & Total \\
\hline AVD & $\begin{array}{c}47 \\
(67.1)\end{array}$ & $\begin{array}{c}115 \\
(82.1 \%)\end{array}$ & $\begin{array}{c}162 \\
(77.1 \%)\end{array}$ \\
\hline EL-LSCS & 0 & $3(2.1 \%)$ & $3(1.4 \%)$ \\
\hline EM-LSCS & $\begin{array}{c}19 \\
(5.7 \%)\end{array}$ & 0 & $\begin{array}{c}4 \\
(1.9 \%)\end{array}$ \\
\hline Column totals & 70 & 140 & $22 \%)$ \\
\hline
\end{tabular}

(NVD = normal vaginal delivery, AVD - assisted vaginal delivery with instruments, EM-LSCS - emergency caesarean delivery, EL-LSCS - elective caesarean delivery) 


\subsection{APGAR score and special care neonatal admissions}

$4.2 \%$ of isolated oligohydramnios babies and $3.3 \%$ of normal pregnancies were had APGAR score $<7$ at 5 minutes. It is not statistically significant $\left(\mathrm{X}^{2}=0.2956\right.$, $\mathrm{p}=0.586$ ). $8.5 \%$ of babies of isolated oligohydramnios and $6.4 \%$ of babies of the control group were admitted to SCBU after delivery and it was statistically significant $\left(\mathrm{X}^{2}-23.56, \mathrm{p}<0.0001\right.$. $)$

Table 7. Comparison of APGAR score at delivery

\begin{tabular}{|l|c|c|c|}
\hline & $\begin{array}{c}\text { Cases } \\
(\%)\end{array}$ & $\begin{array}{c}\text { Control } \\
(\%)\end{array}$ & Total \\
\hline APGAR $<7$ & $3(4.2)$ & $4(2.8)$ & $7(3.3)$ \\
\hline APGAR $>7$ & $\begin{array}{c}67 \\
(95.8)\end{array}$ & $\begin{array}{c}136 \\
(97.2)\end{array}$ & $\begin{array}{c}203 \\
(96.7)\end{array}$ \\
\hline Total & 70 & 40 & 210 \\
\hline
\end{tabular}

Table 8. Comparison of number of SCBU admissions

\begin{tabular}{|l|c|c|c|}
\hline & $\begin{array}{c}\text { Cases } \\
(\%)\end{array}$ & $\begin{array}{c}\text { Control } \\
(\%)\end{array}$ & Total \\
\hline $\begin{array}{l}\text { SCBU } \\
\text { admission }\end{array}$ & $\begin{array}{c}6 \\
(8.5)\end{array}$ & $\begin{array}{c}9 \\
(6.4)\end{array}$ & $\begin{array}{c}15 \\
(7.1)\end{array}$ \\
\hline $\begin{array}{l}\text { No SCBU } \\
\text { admission }\end{array}$ & $\begin{array}{c}64 \\
(91.5)\end{array}$ & $\begin{array}{c}131 \\
(93.6)\end{array}$ & $\begin{array}{c}195 \\
(92.9)\end{array}$ \\
\hline Total & 70 & 140 & 210 \\
\hline
\end{tabular}

$(\mathrm{SCBU}=$ Special care baby unit)

\section{Discussion}

The study was conducted in a sample of 70 pregnant mothers who had isolated oligohydramnios who were admitted to the Teaching Hospital Kandy, and the study group was compared with normal pregnancies. For each case of isolated oligohydramnios, two normal pregnancies were selected as controls. Controls were matched for the age and parity of the study group.
Routine induction policy of the ward 7 at the Teaching Hospital is primi mothers at 40 weeks and 3 days and multigravida at 40 weeks and 6 days. Induction agent of choice is prostaglandin E2. However, in the study population, a significant number of pregnancies with isolated oligohydramnios were induced early compared to normal pregnancies. Reduction in amniotic fluid tends to cause umbilical cord compression and variable decelerations in fetal trace. But, there was no significant difference in pathological CTGs.

Meanwhile, pregnancies with isolated oligohydramnios had significantly increased incidence of meconiumstained amniotic fluid compared to normal pregnancies. When analyzing the mode of delivery, four mothers in the isolated oligohydramnios group underwent elective caesarean section. Also, 27.2\% isolated oligohydramnios mothers and $15.8 \%$ of normal pregnancies ended up in emergency caesarean section and which is a statistically significant difference $\left(\mathrm{X}^{2}=12.98\right.$, $\mathrm{p}=0.003)$. Increased incidence of CTG abnormalities and presence of significant meconium-stained liquor might have contributed to this increase.

However, when comparing the APGAR score at 5 minutes, only 3 pregnancies with isolated oligohydramnios and 4 normal pregnancies had a score of less than 7 at 5 minutes and was not significant difference between the two groups. But, considering the admission to special care baby unit admissions $8.5 \%$ babies of isolated oligohydramnios and $6.4 \%$ of babies of normal pregnancies were admitted to SCBU and was statistically significant.

The main reasons for special care baby unit admissions were tachypnea of newborn, jaundice and suspected sepsis. Even though babies of isolated oligohydramnios had a slight increase in the tendency to have these complications in this study, it was not statistically significant.

\subsection{Relevance of these findings to our health care system}

Even though Sri Lanka is a developing third world country, it provides complete free health care services to the whole population. So, when we are selecting an intervention, it should be safe and cost-effective. As there is conflicting evidence regarding the management of isolated oligohydramnios there must be national protocols/ guidelines in the management of this 
condition. Otherwise, it leads to anxiety among clinicians and which results in more interventions such as more induction of labour and caesarean section without improving neonatal outcomes.

Caesarean section carries more risks to mother in the short term as well as long-term. Also, it increases the short term respiratory complications in the baby. Having a pregnancy with isolated oligohydramnios may increases the anxiety of both pregnant mothers and the obstetrician as there are controversial issues in the management. To overcome these dilemmas more researches are needed in this category of the patients to identify the optimal way of management. Our research indicates that pregnant mothers with isolated oligohydramnios were induced early compared to normal pregnancies without improving short term outcomes. However, we don't know that early interventions might have reducd the adverse outcome associated with isolated oligohydramnios. So further research is needed in this field.

\subsection{Alternative explanations of the findings}

The studies conducted in developing countries reveals the patients who had isolated oligohydramnios had a higher induction rate to prevent adverse pregnancy outcomes. It may indicate a lack of facility for continuous electronic fetal monitoring or fetal blood sampling, which leads to a low threshold ofcaesarean section. The decision to induce early threshold for cesarean is mainly influenced by the unit's policy and available facilities.

\section{Conclusions and recommendation}

This study compared the perinatal outcomes of isolated oligohydramnios with normal pregnancies. The majority of pregnant mothers with IO were induced early and a significant number of them ended up in the emergency caesarean section. Also, the incidence of significant meconium-stained liquor was significantly higher. However, as far as the fetal outcomes are concerned, APGAR score of $<7$ at 5 minutes and short term perinatal morbidities were not significant differences between two groups although higher incidence of neonatal special care unit admissions. But, we have to consider that early and more obstetrics interventions might have exerted a masking effect. Therefore, further large scale randomized controlled studies are needed in this field.

\section{Authors' contributions}

ACMM was the principal author and conceived the topic for this manuscript and both KASUAK and MFMR have done the review. All authors have critically revised and approved the final version of the manuscript

\section{References}

1. Brian S Carter, Polyhydramnios and Oligohydramnios Clinical Presentation, available at http:/ /reference.medscape.com/article/975821-clinical (Accessed on 20 May 2014).

2. Phelan JP, Smith CV, Broussard P, Small M. Amniotic fluid volume assessment with the fourquadrant technique at $36-42$ weeks' gestation. The Journal of Reproductive Medicine. $1987 \mathrm{Jul} ; 32(7)$ : 540-2.

3. Magann EF, Chauhan SP, Washington W, Whitworth NS, Martin JN, Morrison JC. Ultrasound estimation of amniotic fluid volume using the largest vertical pocket containing umbilical cord: measure to or through the cord?. Ultrasound in Obstetrics and Gynecology. 2002 Nov; 20 (5): 464-7.

4. Hina A, Shama M. Isolated oligohydramnios is not an indicator of adverse perinatal outcomes. Journal of Pakistan of the Medical Association 2009 Oct: 691-94.

5. Elsandabesee D, Majumdar S, Sinha S. Obstetricians' attitudes towards 'isolated' oligohydramnios at term. Journal of Obstetrics and Gynaecology. 2007 Aug; 27(6): 574-6.

6. Bachhav AA, Waikar M. Low amniotic fluid index at term as a predictor of adverse perinatal outcome. The Journal of Obstetrics and Gynecology of India. 2014 Apr; 64(2): 120-3.

7. Alchalabi HA, Obeidat BR, Jallad MF, Khader YS. Induction of labor and perinatal outcome: the impact of the amniotic fluid index. European Journal of Obstetrics and Gynecology and Reproductive Biology. 2006 Dec; 129(2): 124-7.

8. Shrem G, Nagaswkar S, Hallak M, Walfisch A. Isolated oligohydramnios at term as an indication for labour induction: systematic review and metaanalysis. Fetal diagnosis and Therapy 2016; 40(3): 161-73. 